rapidly the Physics School at Oxford on a proper scale. Approximately $£ 5,500$ is to be devoted to Nuffield Foundation fellowships, and the donors properly - and somewhat exceptionally - have realized that extra research fellows entail extra expenditure in the way of technical assistants and so forth, and have accordingly made provision for another $£ 2,500$ a year to be used for such purposes. By this judicious and timely gift, Lord Nuffield has greatly added to the debt which science in Britain already owes him.

\section{Science and Culture}

The January issue of Science and Culture (India) is the Science Congress number. The whole issue does credit to its editors and contributors. There are three articles dealing with the Geological Survey of India in both retrospect and prospect. Dr. Joseph Needham, whose articles on science in China have been published periodically in Nature, contributes a very informative review of the National Academy of Peiping and its activities during the War; this is accompanied by a useful map. A reproduction of Prof. Niel Bohr's article on "A Challenge to Civilization" is timely. "For' meeting the challenge to civilization in the proper spirit it should be a most fortunate omen that we have to do with implications of pure scientific studies pursued with no other aim than to widen the borders of our knowledge and to deepen our understanding of that nature of which we ourselves are a part. Let us hope that the science which, through the ages, has stood as a symbol of the progress to be obtained by common human striving, by its latest emphasis on the necessity of concord, may contribute decisively to a harmonious relationship between all nations.'

Prof. S. K. Mitra and Dr. J. N. Bhar contribute a useful article on developments in radar. Apart from more special articles, this issue of Science and Culture contains a number of research announcements in the form of letters to the editors. There are also informative articles on Bangalore and on the general president and the sectional presidents of the Science Congress. It is becoming increasingly clear that every country, or at any rate every cultural group, needs its own general scientific journal. In many cases, such journals already exist; and Science and Culture is one of the best of them. Published monthly, it covers all branches of science, naturally devoting special attention to science in India. We congratulate the editors on this special number, and commend the journal to all men of science and others. It is deserving of all possible support.

\section{Jute Research in India: Prof. B. C. Kundu}

According to Science and Culture (India), of January, Prof. B. C. Kundu, professor of botany in Presidency College, Calcutta, has been appointed director of jute agricultural research, in charge of the Agricultural Research Laboratories, of the Indian Central Jute Committee, at Dacca. Prof. Kundu obtained a first-class master's degree in botany in the University of Calcutta in 1927, being first in order of merit. After a short period of service as a lecturer in botany, Ravenshaw College, Cuttack, he took up research work in the University under Prof. S. P. Agharkar, on being awarded the Sir Rash Behary Ghosh research scholarship. He served as a lecturer in botany, Rajshahi College, Bengal, during 1930-37. In the latter year he proceeded to Britain on study leave, and worked under the late Prof. J. B. Priestley, of the University of Leeds, on the fibre plants of India with special reference to their development, growth and structure. $\mathrm{He}$ has been serving as a professor of botany in Presidency College, Calcutta, and as honorary lecturer in the University of Calcutta, since 1939: During these years he has been working on jute, sunn hemp, Hibiscus and other fibre-yielding plants and has published a number of papers on these in various journals. As honorary secretary of the Botanical Society of Bengal, he has shown noteworthy powers of organisation.

\section{Organisation of Science in Great Britain}

Ar a meeting of the Society of Visiting Scientists on January 23, there was an interesting discussion on the organisation of science in Great Britain, following on papers by Mr. O. F. Brown, of the Department of Scientific and Industrial Research, Mr. J. C. F. Fryer, secretary of the Agricultural Research Council, and Sir Edward Mellanby, secretary of the Medical Research Council. Of the three institutions, the Department of Scientific and Industrial Research appears to be the most centralized, while the Medical Research Council is as nearly independent as a Government department can be; Prof. M. L. Oliphant, in proposing the vote of thanks, was emphatic that this type of organisation is the right one even for applied research. Sir Edward Mellanby stressed that the Medical Research Council never works to a programme but concentrates on the man, letting him go ahead with his particular research and not dictating its conduct. The Council endeavours to encourage research in the universities and hospitals, and particularly the flow of men back to the universities. Dr. Solandt, however, questioned whether more than one in every four or five men of science is good enough to be left free for independent research along self-chosen lines, and suggested the need for one body to survey the overall scientific needs and man-power requirements of the community, so that no field may be left vacant. Mr. Fryer referred, in his address, to this question of shortage of man-power and equipment, and the problem of maintaining an adequate balance between fundamental and applied research. The integration of one field of scientific work with another constitutes a major problem, and he believes that it is such 'bridging,' subjects as soil microbiology, animal husbandry, feeding and pathology that are likely to lead to progress in the future.

Mr. Brown, in reply to a question, explained that the new Production Engineering Section of the Department of Scientific and Industrial Research is concerned with the working of metals and fundamental research on machine tools and not with methods of organisation. Dr. Julian Huxley, discussing the question of co-ordination, commented on the anomal. ous position of the British Museum (Natural History) as the only scientific Government institution in Britain with no scientific advisory committee. $\mathrm{He}$ agrees with the view that horizontal or applied research should be under a central body while fundamental research should come under the various departments ; there is, however, no body concerned primarily with the encouragement of pure biological research. Mr. Brown also expressed the opinion that, in future, such bodies as the Department of Scientific and Industrial Research would be more concerned with fundamental research, while problems of the application and development of research results would be handled by the ministries or by industry. 